\title{
Production of Fresh Water by a Solar Still: An Experimental Case Study in Australia
}

\author{
Elizabeth Nomor, Rafiqul Islam (D), Mohammad A. Alim (1) and Ataur Rahman *, \\ School of Engineering, Design and Built Environment Western Sydney University, Penrith, NSW 2751, Australia; \\ E.Nomor@westernsydney.edu.au (E.N.); R.Islam@westernsydney.edu.au (R.I.); \\ M.Alim@westernsydney.edu.au (M.A.A.) \\ * Correspondence: A.Rahman@westernsydney.edu.au \\ + Kingswood (Penrith Campus), Western Sydney University, Australia, Office: XB.3.43, Locked Bag 1797, \\ Penrith South DC, Sydney, NSW 2751, Australia.
}

Citation: Nomor, E.; Islam, R.; Alim, M.A.; Rahman, A. Production of Fresh Water by a Solar Still: An Experimental Case Study in Australia. Water 2021, 13, 3373. https: / / doi.org/10.3390/w13233373

Academic Editor: Maria Mimikou

Received: 20 October 2021

Accepted: 25 November 2021

Published: 30 November 2021

Publisher's Note: MDPI stays neutral with regard to jurisdictional claims in published maps and institutional affiliations.

Copyright: (c) 2021 by the authors. Licensee MDPI, Basel, Switzerland. This article is an open access article distributed under the terms and conditions of the Creative Commons Attribution (CC BY) license (https:/ / creativecommons.org/licenses/by/ $4.0 /)$.

\begin{abstract}
There is a scarcity of fresh water in many rural communities where solar stills can be used to produce drinking water at a minimal cost. These stills use solar energy, which is a sustainable form of energy, and hence this can contribute towards achievement of United Nations (UN) Sustainable Development Goals (SDG). This study aims to develop empirical models of a solar stills based on experimental data obtained at Werrington South, New South Wales, Australia. Two solar stills were used in the experiment, a conventional design (Con-Still) and a con-still modified with adding extra thermal mass inside the still (mod-still). Regression analysis was adopted to develop prediction equations using $\mathrm{Pi}$ (productivity in $\mathrm{L} / \mathrm{m}^{2} /$ day) as the response variable and ambient temperature $(T a)$, sky temperature (Ts19), global radiation $(G h)$, and wind velocity $(W)$ as the predictor variables. The mean and median productivity values of the mod-still were found to be $17 \%$, and $22 \%$ higher than that those for the con-still. The proposed mod-still can be further improved and used in rural areas to produce fresh water from sea water and other forms of contaminated water.
\end{abstract}

Keywords: solar still; productivity; SDG; fresh water; solar energy

\section{Introduction}

Most developing countries are incapacitated by a lack of funds to afford the central treatment facilities for supplying potable water, which is necessary for good health and socio-economic development. As per the current estimate, there are at least two billion people without adequate clean water [1]. Solar distillation offers a simple solution with thermal processes typical to the earth's hydrological cycle, and this can be used to produce potable water to meet rural household drinking water demand [2].

During solar distillation, a pure form of water is evaporated and condenses on the transparent cover of a still (inclined to aid downward flow), due to the temperature difference between it and the water into a collector [3]. This leaves behind the brine, composed of impurities in the basin liner or floor. The quality of the evaporated yield has hardly been a problem. Ultraviolet rays from the sun render most pathogens inactive this making the condensed drinkable [4]. The main variables affecting water productivity of a solar still are ambient temperature, sky temperature, global radiation and wind velocity.

Researchers are more interested to develop ways for increasing the productivity of a solar still by increasing the efficiency of the processes involved [5]. The produced water in a solar still is one of the cleanest forms of water, but there might be system and surrounding infused quality issues, which is left out of the scope of this study. A solar still's efficiency is greatly affected by climatic factors such as wind velocity and geographic location with respect to latitude [6,7]. Variables such as the brine depth, geometric structure of the still with modifications such as the use of condensers, larger condenser areas, absorbent materials, and fins give a boost to distillate yield in a solar still [8]. The major drawback of a 
solar still is its low water yield since solar energy supply is intermittent. Conventional yields are 3-7 L/day for $1 \mathrm{~m}^{2}$ still area with mean global radiation of $4-8 \mathrm{kWh} / \mathrm{m}^{2}$ day [9-11].

The major quest for innovation for a solar still is how these heat transfer processes can have their wasted heat energy harnessed and recycled to warm up the inlet water feed or be even stored to keep productivity constant even during nocturnal hours. How can these heat processes be engineered to enhance yield of a solar still with insightful manipulations that would increase efficiency, and produce higher yields of potable water?

Recent research has attempted to experiment with various design modifications to increase the yield of a solar still. Most of these modifications are innovations meant to increase the rate of evaporation by increasing the heat in the system. These are mostly by using multistage and stepped styled stills $[12,13]$. This utilised heat, recovered from lower levels, is used to warm up a solar still to increase its efficiency.

The development of innovative design with high yields at below room temperatures reiterates the need to determine which of these phenomena (evaporation or condensation) is more crucial to attaining higher yields in solar distillation. There has been an increased interest in the use of phase change materials, nano-particles, absorbent materials, photovoltaic cells and other solar collection technologies such as the parabolic and hemispherical designs [14]. These are however too complex and advanced for use by rural people.

Therefore, this research aims to use experimental data from two solar stills to develop predictive models for estimating productivity of a solar still. These models incorporate variables relevant to productivity. An additional aim is increasing the performance of a solar still by manipulating the key heat processes factored into the thermal processes of evaporation, capillary action, and condensation.

\section{Materials and Methods}

Two solar stills were constructed in Werrington South Campus of Western Sydney University, New South Wales (NSW), Australia. The mean annual rainfall at the study location is $721 \mathrm{~mm}$, with February being the wettest $(122 \mathrm{~mm})$ and July the driest $(29 \mathrm{~mm})$. The clear sky is more prominent during late June to early October and the cloudiest month is November when the sky is overcast or mostly cloudy $37 \%$ of the time. The clearest month is August when the sky is clear, mostly clear, or partly cloudy $78 \%$ of the time. In Sydney, December is the sunniest month with $257 \mathrm{~h}$ of sunshine, and May has the lowest amount of sunshine with about $180 \mathrm{~h}$. The average annual sun hours are $2600 \mathrm{~h}$. The average annual solar exposure/radiation on the ground surface for the study location is $15.8 \mathrm{MJ} / \mathrm{m}^{2}(8.5 \mathrm{in}$ June and $21.7 \mathrm{MJ} / \mathrm{m}^{2}$ in January).

The two stills had an identical design, except for the placement of charcoal-colored concrete pavers in one of them as the modified version. The Unit 1, conventional solar still (called con-still), was intended to have its productivity compared with the modified version, Unit 2 (called mod-still). The objective was to examine the impacts of pavers on the solar-still yield. This is based on claims from several reviewed literatures that increasing the heat capacity for higher productivity attempted with components that are expected to increase output of a solar still $[15,16]$.

The setup in the mod-still had charcoal concrete pavers to aid the heat storage for diurnal production in the basin structure. The weather conditions in the environment were measured to validate their impact on the productivity of the stills and allow for improvements on the present design based on predictive analysis. The comparison between the two stills was carried out using boxplots and several statistics such as median relative error.

The solar still experimental setup is illustrated in Figure 1. The setup was made in an open field with the glass surface facing northwards to ensure reception of solar irradiance throughout the day. Data were collected over 55 days in the summer season (14 December 2019 to 6 February 2020). Both the solar stills were elevated on two $1165 \mathrm{~mm} \times 1165 \mathrm{~mm} \times 144 \mathrm{~mm}$ wooden platforms (Figure 2) to accommodate the brine drain and maintain stability of the structure. This was intended to reduce staining of the 
glass cover due to splattering mud from the ground during rain. This also gave a baseline for easy viewing of both the stills and access to monitoring and collecting data

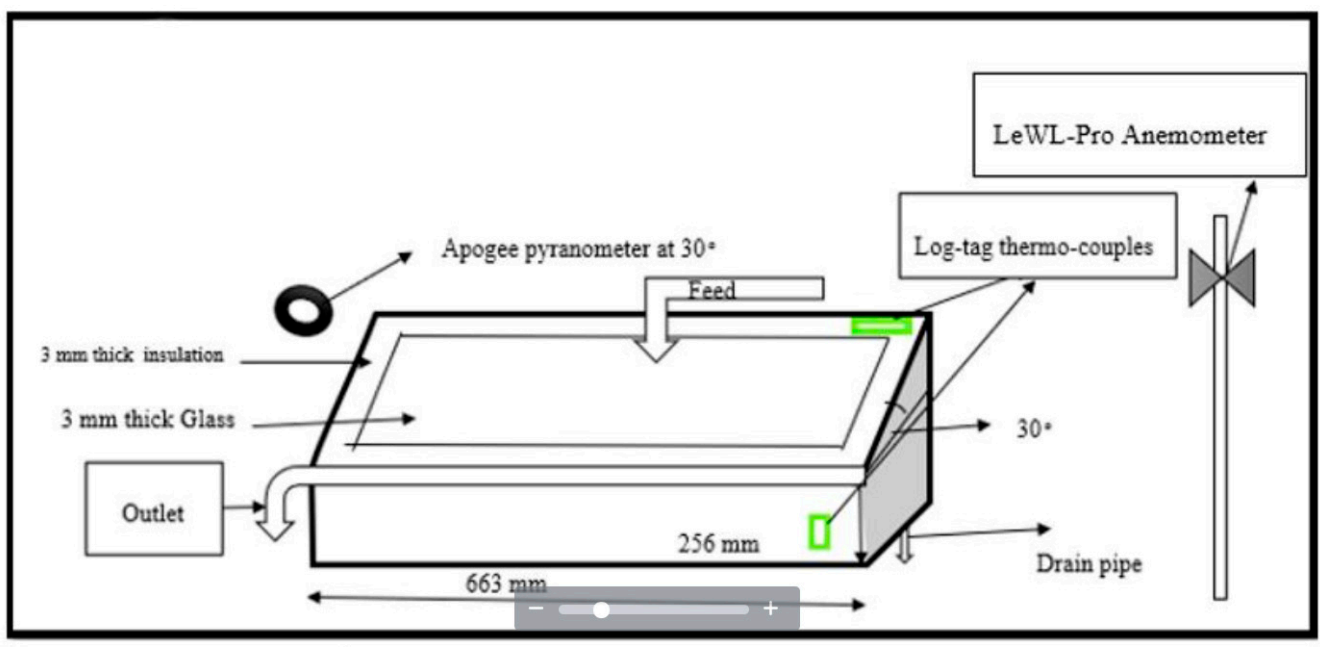

Figure 1. Experimental setup of solar still.

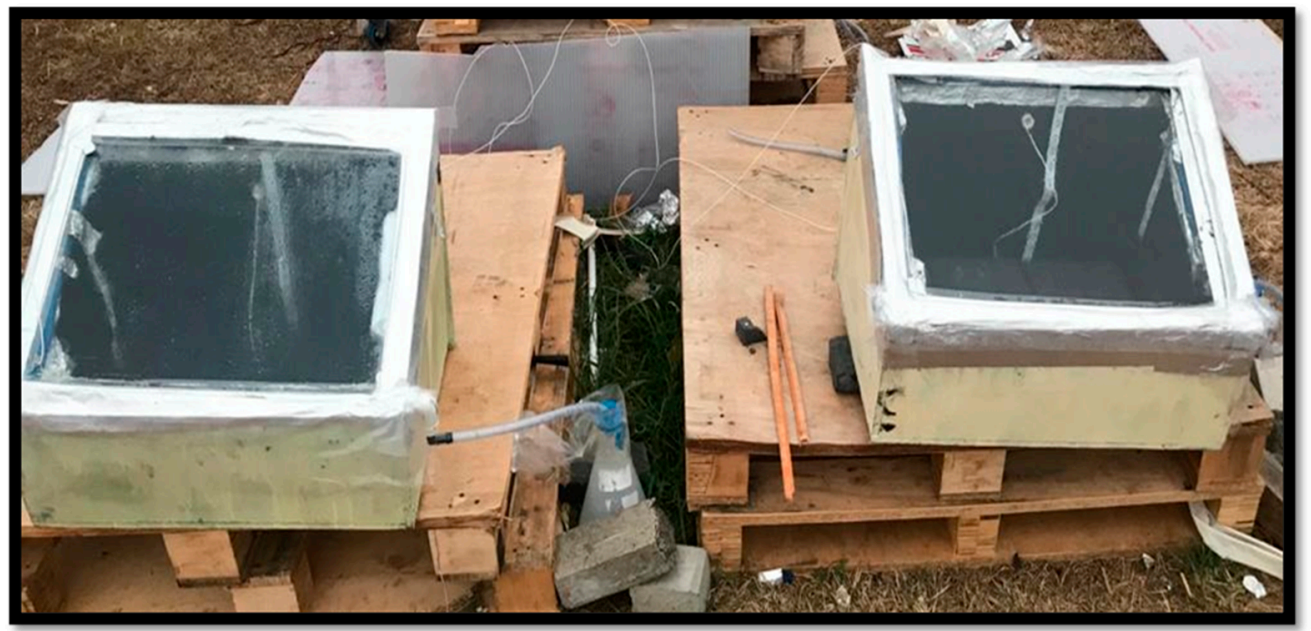

Figure 2. Experimental setup of con-still (left) and mod-still (right).

The initial feeding was 10 litres of stormwater resulting in depths of 5.08 and $12.7 \mathrm{~cm}$ for the Con-Still and Mod-Still, respectively. The collection of distillate data was made daily. The climate data loggers were checked fortnightly to ensure that they were in working order. The operation (feeding, data collection and cleaning) of both the stills was conducted uniformly to enhance consistency of data for comparative analysis. The setup in Figure 2 is a snapshot of both the stills, which were placed side by side on pallets.

Prediction equation was developed by regression analysis employing statistical software Minitab ${ }^{\circledR}$ (Pennsylvania State University, Philadelphia, PA 19104, USA) where measured productivity value $(\mathrm{Pi})$ of the still was used as response variable.

The development of the prediction equations was carried out with the following response $(\mathrm{Pi})$ and predictor variables:

i. Productivity $P i$, liters $/ \mathrm{m}^{2}$ day.

ii. Estimated average global radiation exposure $(G h)$ in $\mathrm{MJ} / \mathrm{m}^{2} /$ day.

iii. Measured average ambient temperature $(\mathrm{Ta})$ in Kelvin.

iv. Average wind speed $(W)$ in $\mathrm{m} / \mathrm{s}$.

v. $H C 1$, is the indicative convective heat transfer factor due to wind and ambient temperature as defined by Equation (1). 
where:

$$
H C 1=T a \times W^{z}
$$

The value of $z$ is to be determined by the best fit of the $H C 1$ with productivity [17] This can vary between 0.2 and 0.5 . For this experiment we found $z=0.25$ giving the best correlation.

i. Product of $\mathrm{Ta}$ and $\mathrm{W}=\mathrm{TaW}, \mathrm{K} \mathrm{m} / \mathrm{s}$.

ii. Average sky temperature (Ts19) in Kelvin.

To carry out a regression analysis, the collated data was organised as below. Ts19 is the sky temperature, which was compiled using Equations (2) and (3):

$$
\begin{gathered}
T s 19=\varepsilon^{1 / 4} T_{a} \\
\varepsilon=C_{1}+C_{2} T_{a}+C_{3}
\end{gathered}
$$

where $C_{1}=-0.34, C_{2}=-0.00336$ and $C_{3}=0.14, T_{a}$ is ambient temperature and $\varnothing$ is relative humidity expressed as a fraction.

Daily productivity values $(\mathrm{Pi})$ were calculated with the volume collected per day and cross-sectional area of still basin using Equation (4):

$$
P i=\frac{\text { Volume of distillate (litres) per day }}{\text { Area of still basin }\left(m^{2}\right)}
$$

The following statistical measures were used for comparing the regression equations:

$$
\begin{gathered}
\text { Relative error }(R E)(\%)=\frac{\text { Predicted value }- \text { Observed value }}{\text { Observed value }} \times 100 \\
\text { Absolute relative error }(A R E)=\text { Absolute value of } R E(\%) \\
\text { Ratio of predicted and observed production }=\frac{\text { Predicted value }}{\text { Observed value }}
\end{gathered}
$$

The following three model forms (Equations (8)-(10)) were adopted:

Model Equation (1):

$$
P i=a+b(G h)+c(T s 19)+d(H C 1)
$$

Model Equation (2):

$$
P i=a+b(G h)+c(T s 19)
$$

Model Equation (3):

$$
P i=a+b(G h)+e(T a)+f(W)-g(T a W)
$$

where $a, b, c, \ldots$ are regression coefficients. The data of the independent variables were measured at $10 \mathrm{~min}, 20 \mathrm{~min}$, and hourly intervals, then averaged over the day to obtain the daily average value. The diurnal values of these variables were taken for the period of $8 \mathrm{pm}$ of day 1 to $7 \mathrm{pm}$ of day two. The daily productivity data and the independent variables were then exported to statistical package Minitab $18^{\circledR}$ for multiple regression analysis. Residual plots, boxplots and scatter plots were generated to assess the validity of the developed regression equations. To assess the model fit, coefficient of determination $\left(R^{2}\right)$ and adjusted coefficient of determination ( $R^{2}$ adjusted) were used. The $R^{2}$ value indicates how well the predicted values by a model match with the observed values. The value of $R^{2}$ varies between 0 to 1 , where a value of zero indicates no correlation and 1 indicates a perfect correlation. The variance inflation factor (VIF) was used to check the degree of correlation among the independent variables. A VIF value of 2.0 indicates no correlation among the independent variables. Standard error of estimate (SE) was used to indicate the expected error of the developed model. A regression model with higher $R^{2}$ and smaller SE is preferable. 


\section{Results}

The summary of Models 1, 2, and 3 for con-still is presented in Tables 1-3. The analysis of variance (ANOVA) is presented in the supplementary section for Model 1 (Table S1). The ANOVA for all the models showed that the overall regression had a very small $p$-value (smaller than 0.01), which indicated that the developed equations were significant at the level of $1 \%$ significance level. The $R^{2}$ values of Models 1, 2 and 3 are $37.40 \%, 37.45 \%$ and $43.14 \%$, respectively, which indicate that Model 3 has the best goodness-of-fit. Although there is a mild reduction of standard error and improvement of $R^{2}$ in Model 2 compared to Model 1, it is not a notable gain. Therefore, it can be concluded that the sky temperature alone may not be the best predictor to account for cooling effect required to balance the relationship between the daily evaporation and condensation. This necessitated the introduction of a convective cooling term involving wind and ambient temperature in Model 3. For all the three models, the VIF values are much different to 2.00, which indicates that the adopted predictor variables are moderately correlated among themselves.

Table 1. Model summary for con-still (Model 1).

\begin{tabular}{|c|c|c|c|c|c|}
\hline \multicolumn{6}{|c|}{ Model Summary } \\
\hline$S$ & $R^{2}$ & \multicolumn{2}{|c|}{$R^{2}$ (Adjusted) } & \multicolumn{2}{|c|}{$R^{2}$ (Predicted) } \\
\hline 0.79 & $37.40 \%$ & \multicolumn{2}{|c|}{$35.00 \%$} & \multicolumn{2}{|c|}{$21.13 \%$} \\
\hline \multicolumn{6}{|c|}{ Coefficients } \\
\hline Term & Coefficient & SE Coefficient & $T$-Value & $p$-Value & VIF \\
\hline Constant & -26.865 & 10.58 & -2.54 & 0.014 & \\
\hline Gh & 0.076 & 0.020 & 3.80 & 0.001 & 1.12 \\
\hline Ts19 & 0.091 & 0.036 & 2.63 & 0.011 & 1.11 \\
\hline \multicolumn{6}{|c|}{ Regression Equation } \\
\hline
\end{tabular}

$S$, standard error of estimate, $R^{2}$, Co-efficient of determination, SE, standard error, $p$, probability, VIF, variance inflation factor.

Table 2. Model summary for con-still (Model 2).

\begin{tabular}{|c|c|c|c|c|c|}
\hline \multicolumn{6}{|c|}{ Model Summary } \\
\hline$S$ & $R^{2}$ & \multicolumn{2}{|c|}{$R^{2}$ (Adjusted) } & \multicolumn{2}{|c|}{$R^{2}$ (Predicted) } \\
\hline 0.79 & $37.45 \%$ & \multicolumn{2}{|c|}{$35.04 \%$} & \multicolumn{2}{|c|}{$27.80 \%$} \\
\hline \multicolumn{6}{|c|}{ Coefficients } \\
\hline Term & Coefficient & SE Coefficient & $T$-Value & $p$-Value & VIF \\
\hline Constant & -26.9 & 10.6 & -2.54 & 0.014 & \\
\hline Gh & 0.075 & 0.019 & 3.81 & 0.000 & 1.12 \\
\hline Ts19 & 0.095 & 0.036 & 2.63 & 0.011 & 1.12 \\
\hline \multicolumn{6}{|c|}{ Regression Equation } \\
\hline & & $=-26.9+0.075$ & 0.951 Ts19 & & \\
\hline
\end{tabular}


Table 3. Model summary for con-still (Model 3).

\begin{tabular}{|c|c|c|c|c|c|}
\hline \multicolumn{6}{|c|}{ Model Summary } \\
\hline$S$ & $R^{2}$ & \multicolumn{2}{|c|}{$R^{2}$ (Adjusted) } & \multicolumn{2}{|c|}{$R^{2}$ (Predicted) } \\
\hline 0.77 & $43.14 \%$ & \multicolumn{2}{|c|}{$38.59 \%$} & \multicolumn{2}{|c|}{$10.68 \%$} \\
\hline \multicolumn{6}{|c|}{ Coefficients } \\
\hline Term & Coefficient & SE Coefficient & $T$-Value & $p$-Value & VIF \\
\hline Constant & -76.3 & 26.1 & -2.93 & 0.005 & \\
\hline Gh & 0.0640 & 0.020 & 3.20 & 0.002 & 1.20 \\
\hline $\mathrm{Ta}$ & 0.2609 & 0.087 & 2.98 & 0.004 & 7.71 \\
\hline$W$ & 115.5 & 58.5 & 1.97 & 0.054 & 7289.52 \\
\hline $\mathrm{TaW}$ & -0.386 & 0.195 & -1.98 & 0.053 & 7214.19 \\
\hline \multicolumn{6}{|c|}{ Regression Equation } \\
\hline \multicolumn{6}{|c|}{$P i=-76.3+0.0640 \mathrm{Gh}+0.2609 \mathrm{Ta}+115.5 \mathrm{~W}+0.386 \mathrm{TaW}$} \\
\hline
\end{tabular}

The $p$-values for predictors $G h$ and $T a$ are smaller than 0.05 , which indicate that they are significant in Model 3 at $5 \%$ level of significance. The $p$-values for the wind velocity $(W)$ and its product with the ambient temperature $(\mathrm{TaW})$ are 0.054 and 0.053 , which are smaller than 0.10 (i.e., these are also significant in Model 3 at $10 \%$ level of significance). This indicates that the wind velocity $(W)$ is less significant to productivity than the solar radiation $(G h)$ and ambient temperature (Ta). As $W$ is only a relevant enhancement factor for condensation but has substitutes such as the sky temperature, which also influences cooling. As anticipated from the learnings of Model 1 and Model 2, the addition of ambient temperature, wind velocity together and the use of their product as a third variable improved the correlation further thus an improved model overall.

The model diagnostics for Models 1, 2, and 3 for the con-still (can be seen in the supplementary section, Figures S1-S3) revealed that the standardised residuals closely followed the normal distribution and the plot of fitted values and the standardised residuals did not show any notable patterns and $90 \%$ of the standardised residuals were seen to have fallen between \pm 2.00 . These plots showed that the assumptions of multiple linear regressions were well satisfied by these models for con-still. There were few outliers, which could be attributed to abnormal climatic conditions, such as heat wave, cloudy sky and high wind and relative humidity, which would have affected condensation. There was a fair bit of concentration of predicted data points around the ' 0 ' mark, showing a good degree of prediction by Model 3.

Figure 3 presents a boxplot of the productivity values obtained by predictive Models 1 , 2 , and 3 for the Con-Still. The first quartiles for all the three models are 1.84, 1.93, and 1.95 for Models 3, 2, and 1, respectively. The width of the box for Model 2 is smallest as compared to those of Model 1 and Model 3, which indicates the smallest variability in prediction by Model 2. The overall variability for Model 3 is the highest among the three models, which could be attributed to the highest number of predictors in Model 3.

Figure 4 presents a boxplot of the relative error values for Models 1,2, and 3 of the Con-Still. For Model 2, the median value is closest to the 0-0 line indicating that this model has the lowest bias. The widths of the boxes are remarkably similar for the three models, which indicate a similar degree of variance in the model predictions for most of the data points. All the three models have four outlying data points, which indicate that from the entire data, four out of 55 cases (i.e., about $7 \%$ ), there is gross over prediction of productivity by these models. The reason for these outliers could be data error or model inadequacy. 


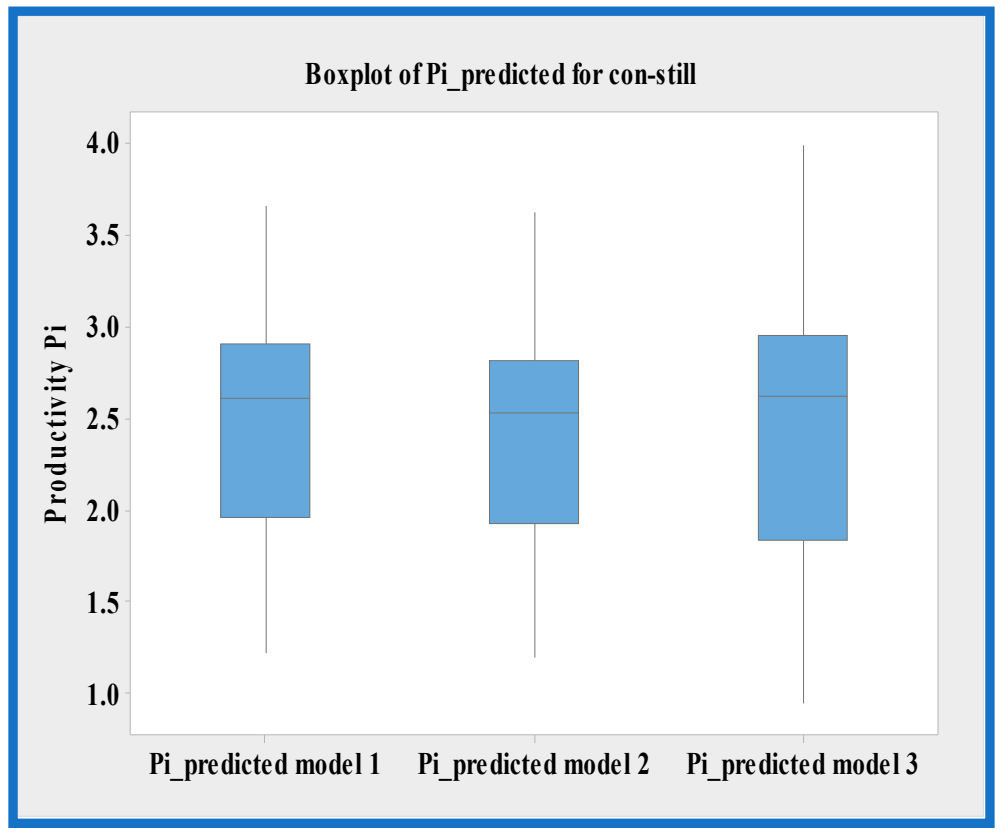

Figure 3. Boxplot of predicted productivity values ( $\mathrm{L} / \mathrm{m}^{2}$ day) by Models 1,2 , and 3 (Con-Still).

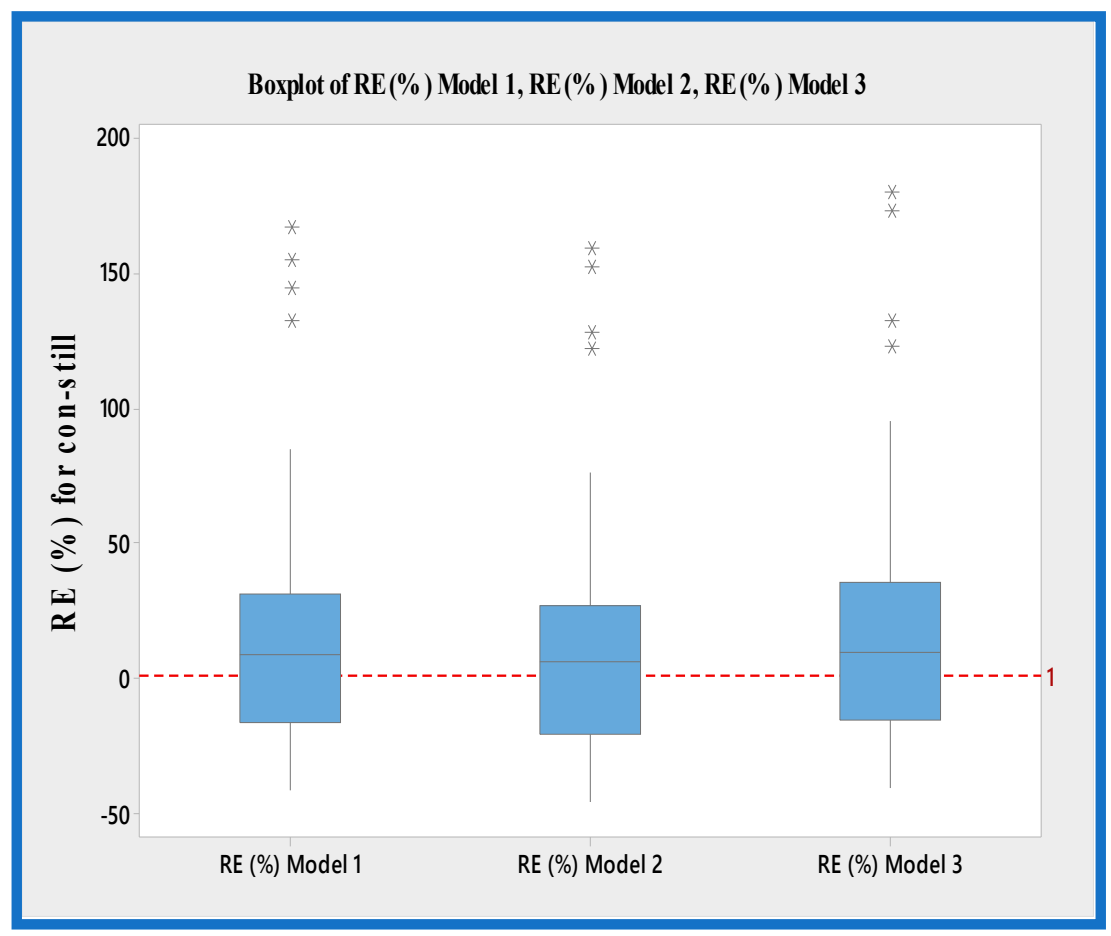

Figure 4. Boxplot comparing relative error (RE) values of Models 1, 2, and 3 (con-still). (Here the * sign represents outlier data points).

Figure 5 presents a boxplot comparing the ratio of predicted and observed productivity values of Models 1, 2, and 3 for the con-still. A reference line was drawn through 1-1 for all the three models. The median value is the closest to 1-1 line for Model 3. The widths of the boxes are remarkably similar for all the three models. Furthermore, there are four outliers for each of these models. A previous identification of the source of the outliers, coupled with a filtering approach, could have produced better performing models. These outliers are mostly due to unexpected productivity values, which were due to low condensation in the still, due to extremely elevated temperatures in summer during the study period. The 
experimental factors can be said to have considerable influence in the study and further controlled studies are suggested.

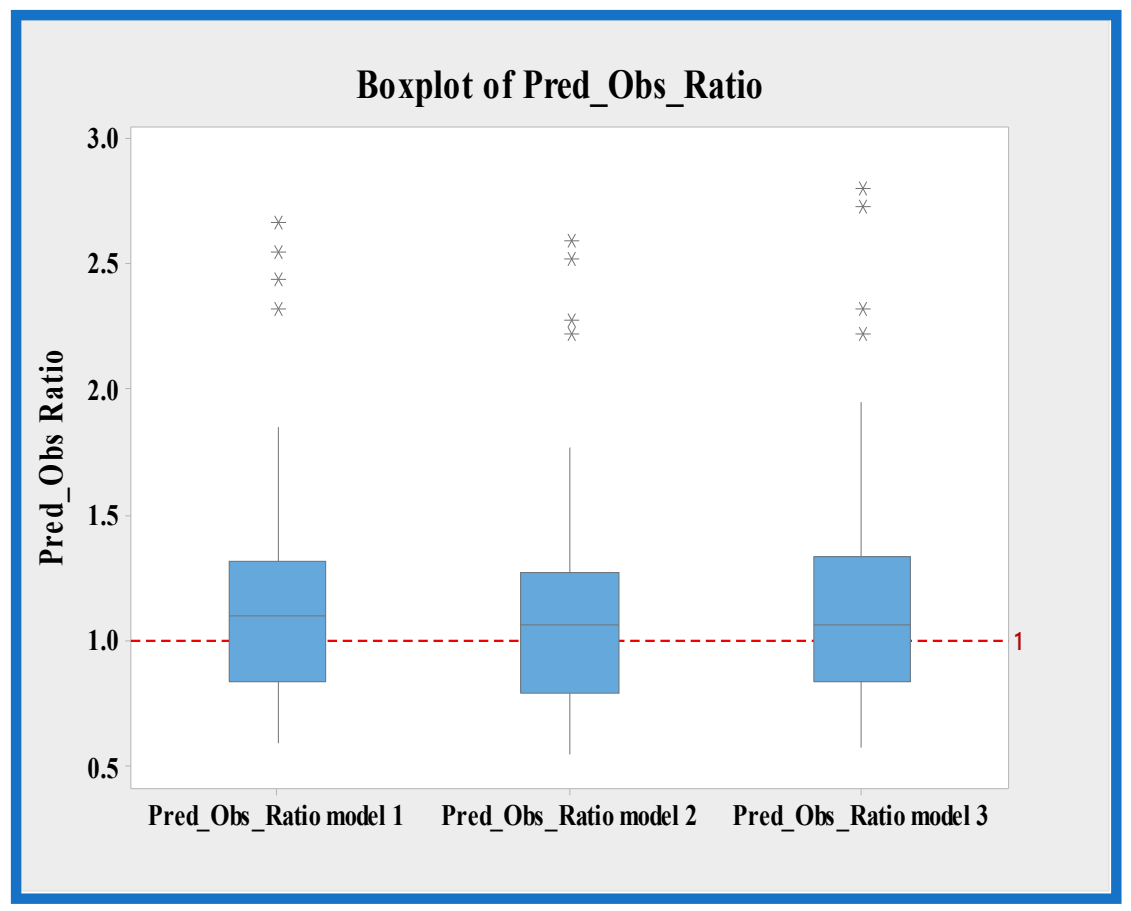

Figure 5. Boxplot comparing the ratio of predicted and observed productivity values of Models 1, 2, and 3 (con-still). (Here the * sign represents outlier data points).

Table 4 presents the model equations alongside their $R^{2}$ values for Models 1, 2, and 3 for the Con-Still. Model 3 has the highest $R^{2}$ value of $43.14 \%$, which represents the best fitting among the three models. Model 3 is the best predictive model equation for the Con-Still with its predictor variables of $G h, T a, W$, and the product $T a W$. This could be due to the recognition of the average wind velocity $(W)$ as a significant variable in the model. Model 1 and Model 2 have remarkably similar $R^{2}$ values, which are about $6 \%$ smaller than Model 3. If considering the $R^{2}$ value, median relative error, mean relative error, median predicted to observed ratio value, relative root mean squared error and standard error of estimate, Model 3 is the best model for con-still.

Table 4. Three generated models for con-still.

\begin{tabular}{ccc}
\hline Con-Still Model & Model Equation & $\boldsymbol{R}^{\mathbf{2}} \mathbf{( \% )}$ \\
\hline Model 1 & $P i=-26.865+0.076 \mathrm{Gh}+0.091 \mathrm{Ts} 19$ & 37.4 \\
Model 2 & $P i=-26.9+0.0755 \mathrm{Gh}+0.951 \mathrm{Ts} 19$ & 37.45 \\
Model 3 & $P i=-76.3+0.0640 \mathrm{G} h+0.2609 \mathrm{Ta}+115.5 \mathrm{~W}+0.386 \mathrm{TaW}$ & 43.14 \\
\hline
\end{tabular}

Tables 5-7 present the summary of Models 1, 2, and 3, respectively, for the modified stills (mod-still). The $R^{2}$ values for Models 1, 2, and 3 for the mod-still are $66.43 \%, 68.48 \%$, and $69.11 \%$, respectively. Overall, the $R^{2}$ values of the mod-still are higher than the constill. This can be attributed to the presence of the pavers in the mod-still, which has a heat storage media. The production rates for the mod-still were found to be more stable over the days, due to a lower volume of residual water per unit volume in the still. This optimises evaporation rates due to lower mass of water allowed by the pavers since both the stills were constructed with a similar design and tested in the same climate and placed side by side. The VIF values for the predictors in the three models are in the range of 1.11 to 1.31 except for $T a$, which indicates that these three variables are highly correlated. The $p$-value for the global radiation factor $(G h)$ seemed to have higher significance than 
the sky temperature (Ts19). This agrees with numerous literatures on the relevance of the global radiation in solar distillation technology.

Table 5. Model summary for mod-still (Model 1).

\begin{tabular}{|c|c|c|c|c|c|}
\hline \multicolumn{6}{|c|}{ Model Summary } \\
\hline$S$ & $R^{2}$ & \multicolumn{2}{|c|}{$R^{2}$ (Adjusted) } & \multicolumn{2}{|c|}{$R^{2}$ (Predicted) } \\
\hline 0.65 & $66.43 \%$ & \multicolumn{2}{|c|}{$66.21 \%$} & \multicolumn{2}{|c|}{$61.91 \%$} \\
\hline \multicolumn{6}{|c|}{ Coefficients } \\
\hline Term & Coefficient & SE Coefficient & $T$-Value & $p$-Value & VIF \\
\hline Constant & -20.841 & 9.18 & -2.38 & 0.021 & \\
\hline Gh & 0.152 & 0.017 & 8.72 & 0.001 & 1.10 \\
\hline Ts19 & 0.069 & 0.034 & 2.19 & 0.026 & 1.31 \\
\hline \multicolumn{6}{|c|}{ Regression Equation } \\
\hline \multicolumn{6}{|c|}{$P i=-20.84+0.152 G h+0.069 T s 19$} \\
\hline
\end{tabular}

Table 6. Model summary for mod-still (Model 2).

\begin{tabular}{|c|c|c|c|c|c|}
\hline \multicolumn{6}{|c|}{ Model Summary } \\
\hline$S$ & $R^{2}$ & \multicolumn{2}{|c|}{$R^{2}$ (Adjusted) } & \multicolumn{2}{|c|}{$R^{2}$ (Predicted) } \\
\hline 0.65 & $68.48 \%$ & \multicolumn{2}{|c|}{$67.25 \%$} & \multicolumn{2}{|c|}{$63.02 \%$} \\
\hline \multicolumn{6}{|c|}{ Coefficients } \\
\hline Term & Coefficient & SE Coefficient & $T$-Value & $p$-Value & VIF \\
\hline Constant & -22.45 & 8.64 & -2.60 & 0.012 & \\
\hline Gh & 0.1441 & 0.0163 & 8.83 & 0.000 & 1.11 \\
\hline Ts19 & 0.0780 & 0.02945 & 2.64 & 0.011 & 1.11 \\
\hline \multicolumn{6}{|c|}{ Regression Equation } \\
\hline \multicolumn{6}{|c|}{$P i=-22.45+0.1441 G h+0.0780 T s 19$} \\
\hline
\end{tabular}

The $p$-value for TaW was greater than 0.10 , which is indicative of low significance, since the Mod-Still has its peak performance at temperatures that are average when compared to the entire data set. Since higher temperatures meant the mod-still was disadvantaged with lower condensation. These temperatures were between 23 to $27^{\circ} \mathrm{C}$, if solar radiations on the previous day were seen to have been extremely high at ranges of 19 to $23 \mathrm{MJ} / \mathrm{m}^{2} /$ day. This meant that the mod-still had the potential for heat storage on the previous day and was allowed enough cooling on the following day with a lower ambient temperature. The dynamics of heat storage in the system is advantageous to higher productivity when the thermal capacity of the mod-still is not overloaded, without the necessary balance of cooling required for condensation. Both phenomena must be provided for to have an efficient still system. 
Table 7. Model summary for the mod-still (Model 3).

\begin{tabular}{|c|c|c|c|c|c|}
\hline \multicolumn{6}{|c|}{ Model Summary } \\
\hline$S$ & $R^{2}$ & \multicolumn{2}{|c|}{$R^{2}$ (Adjusted) } & \multicolumn{2}{|c|}{$R^{2}$ (Predicted) } \\
\hline 0.66 & $69.11 \%$ & \multicolumn{2}{|c|}{$68.78 \%$} & \multicolumn{2}{|c|}{$62.28 \%$} \\
\hline \multicolumn{6}{|c|}{ Coefficients } \\
\hline Term & Coefficient & SE Coefficient & $T$-Value & $p$-Value & VIF \\
\hline Constant & -27.23 & 23.0 & -1.35 & 0.184 & \\
\hline Gh & 0.121 & 0.014 & 8.12 & 0.000 & 1.21 \\
\hline $\mathrm{Ta}$ & 0.104 & 0.072 & 1.34 & 0.083 & 6.52 \\
\hline \multicolumn{6}{|c|}{ Regression Equation } \\
\hline \multicolumn{6}{|c|}{$P i=-29.5+0.1394 G h+0.1013 \mathrm{Ta}$} \\
\hline
\end{tabular}

Table 8 compiles model statistics for Models 1, 2, and 3 for the mod-still. The lowest median RE\% is found for Model 1 whereas the mean RE\% is seen for Model 2. In terms of median predicted to observed ratio values, Model 2 outperforms Model 1 and Model 3. In terms of RBias, Model 2 is also the best performer. In terms of RRMSE (relative root mean squared error) and $S$, all the three models perform equally. Since Model 2 has the lowest values for mean relative error, median and mean predicted versus observed ratio, relative bias and RBias and the standard error of estimate, it is considered to be the best model among the three models for the mod-still.

Table 8. Comparison of model statistics for Models 1, 2, and 3 (mod-still).

\begin{tabular}{|c|c|c|c|c|c|c|c|}
\hline Model & Median RE (\%) & Mean RE (\%) & $\begin{array}{c}\text { Median } \\
\text { Pred_Obs_Ratio }\end{array}$ & $\begin{array}{c}\text { Mean } \\
\text { Pred_Obs_Ratio }\end{array}$ & RBias & RRMSE & $S\left(L / m^{2}\right.$ Day $)$ \\
\hline Model 1 & 12.32 & 22.21 & 1.04 & 1.09 & 9.11 & 0.221 & 0.65 \\
\hline Model 2 & 13.07 & 22.05 & 1.03 & 1.08 & 8.72 & 0.223 & 0.65 \\
\hline Model 3 & 13.21 & 22.58 & 1.05 & 1.10 & 10.22 & 0.214 & 0.66 \\
\hline
\end{tabular}

Figure 6 presents a boxplot of the predicted productivities of Models 1, 2 and 3 of the mod-still. The box widths are remarkably similar for the three models. All three models have their median productivity values around $2.8 \mathrm{~L} / \mathrm{m}^{2}$ day mark, which is quite reasonable since the mean observed productivity for the mod-still is $2.83 \mathrm{~L} / \mathrm{m}^{2}$ day. Overall, all three models have an equal distribution of predicted values over their quartiles. This signifies that their performance is similar with only a minor disparity.

Figure 7 presents boxplot of RE (\%) for Models 1, 2, and 3 of the mod-still. All three models have their median value remarkably close to $0-0$ reference line. Model 2 has the least number of outliers as compared to the other two models. The widths of the boxes are remarkably similar for the three models. Overall, the three models show similar level of accuracy in prediction for majority of cases.

Figure 8 presents boxplot of the ratios of predicted and observed productivity values for the mod-still. All the three models show a mild over prediction. From observed behaviour of outliers, Model 1 has the furthest outlier and Model 3 has the greatest number of outliers. This is since Model 2 had factored in the sky temperature, which explained for conditions required for condensation, whereas the other models did not. 


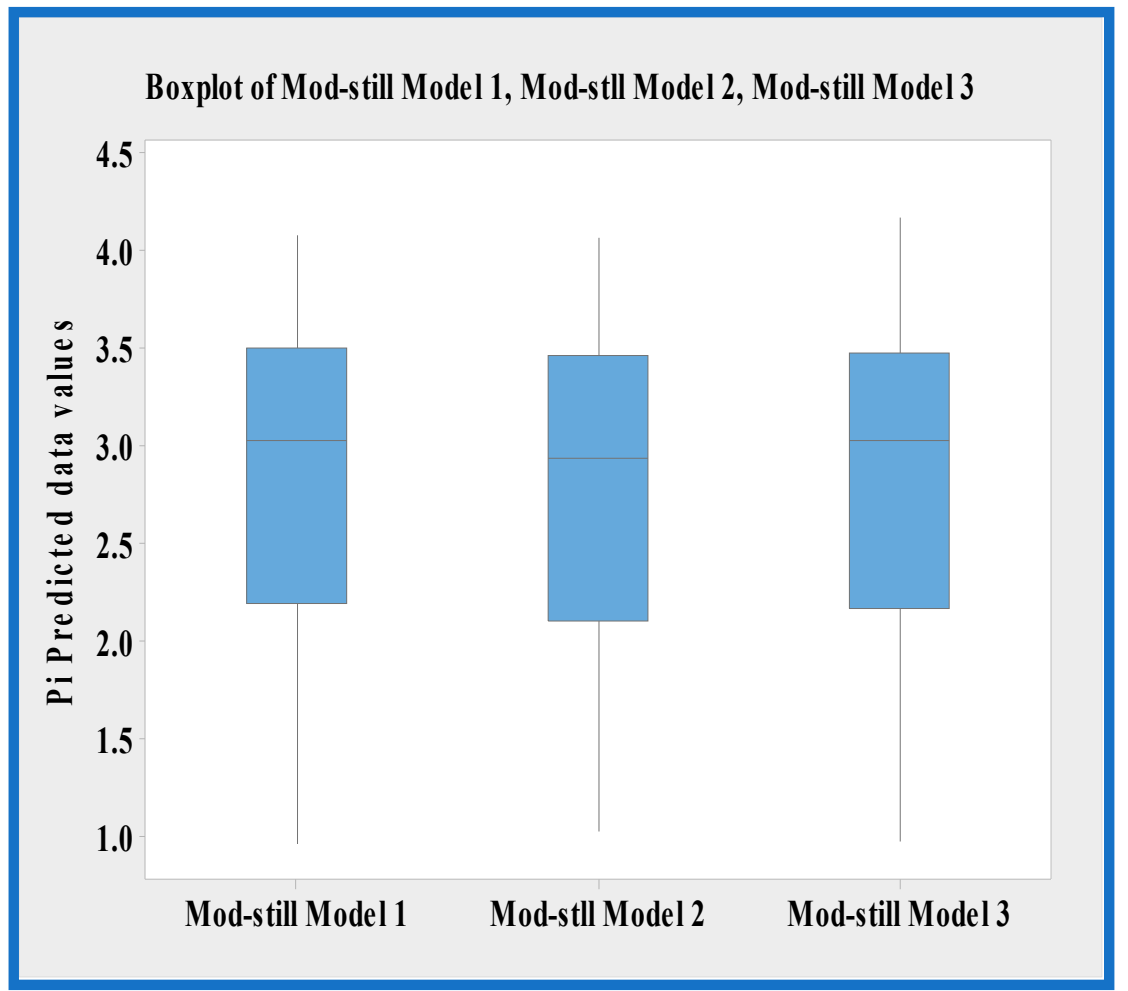

Figure 6. Boxplot comparing productivities by Models 1, 2, and 3 (mod-still).

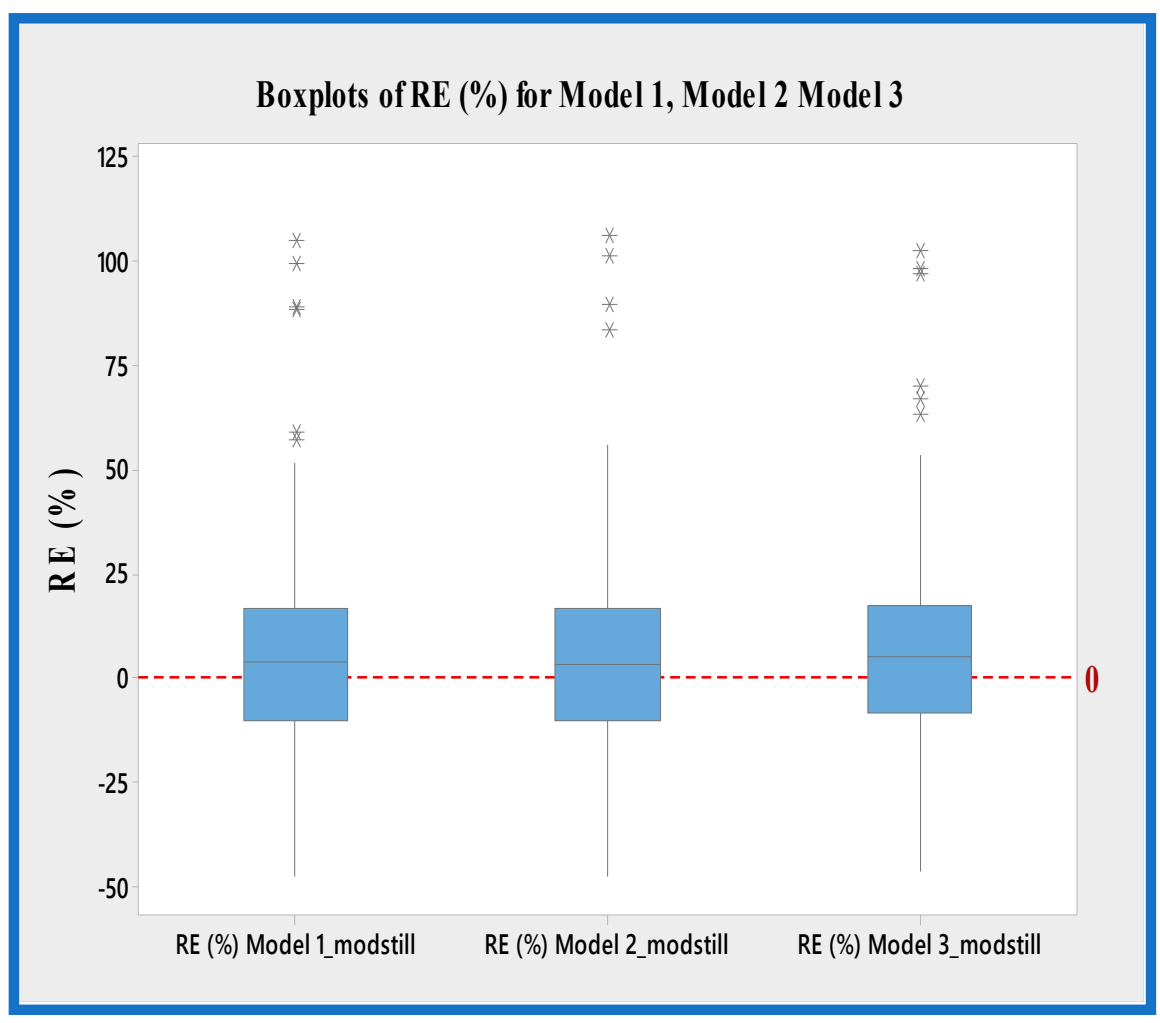

Figure 7. Relative error RE (\%) of Models 1, 2, and 3 (mod-still). (* represents outlier data). 


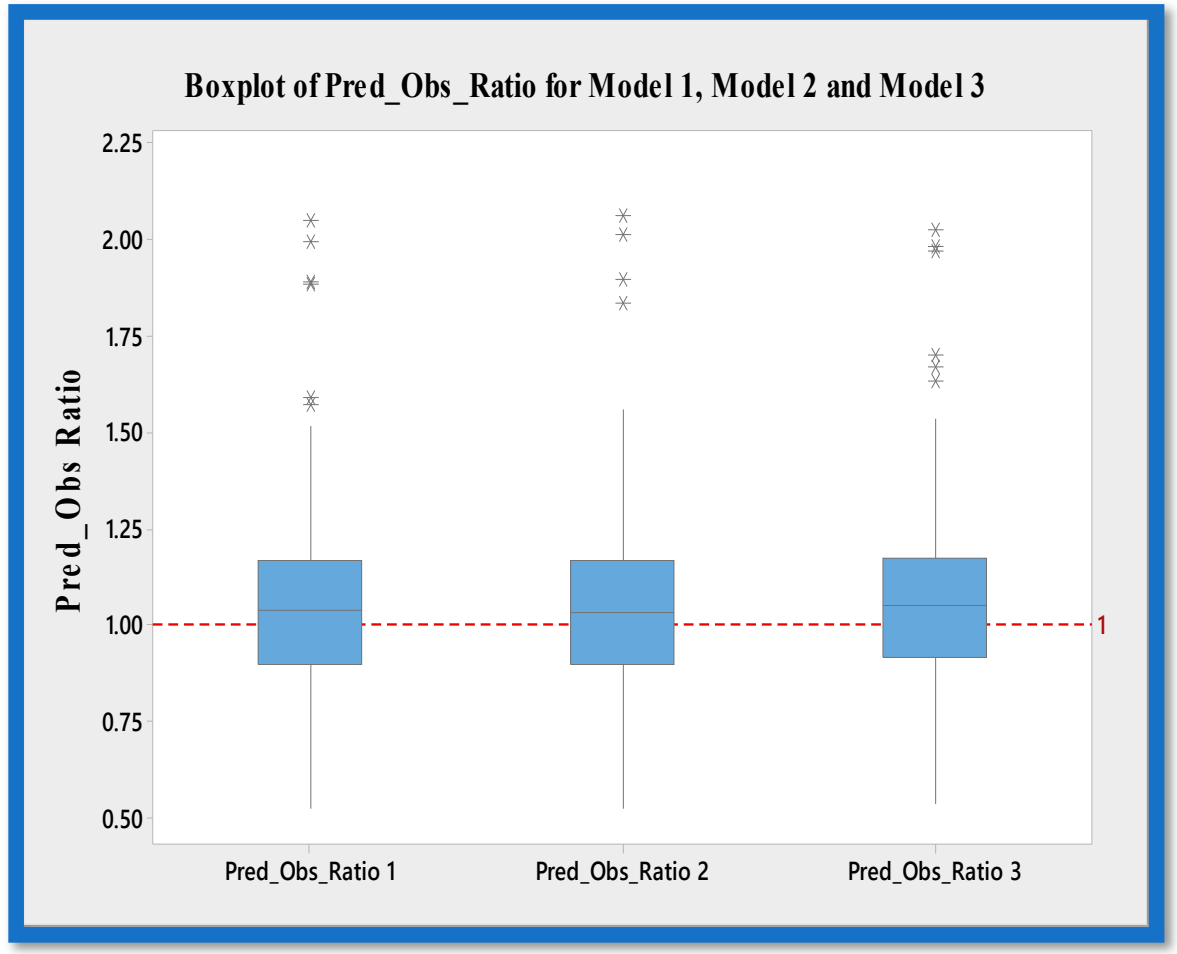

Figure 8. Boxplot of Pred_Obs Ratio of Models 1, 2, and 3 (mod-still). (* represents outlier data).

Figure 9 shows a boxplot comparing the productivity of the con-still and mod-still. It is evident that the modified version of the still with incorporated pavers in the basin had higher productivity values. The $25 \%$ quartile of the mod-still is almost equal to the median value of the con-still. Both have equal minimum and maximum values, with the mod-still being a bit higher for each. This can be attributed to the amount of extra heating made available during diurnal hours by the pavers due to their characteristic thermal conductivity.

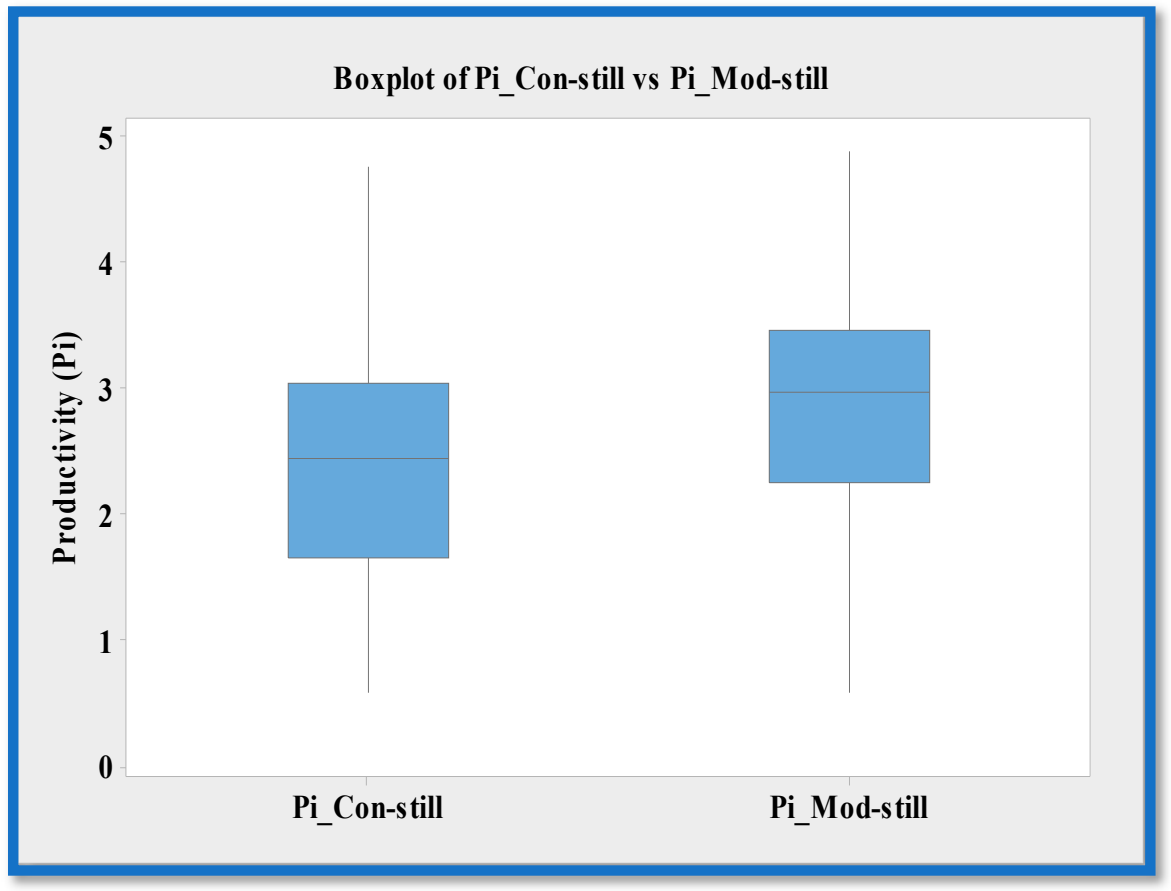

Figure 9. Boxplot of observed productivity values for the con-still and mod-still. 
Table 9 presents the mean, median, and standard deviation of the observed productivity values for both the solar stills. The mean productivity is $2.83 \mathrm{~L} / \mathrm{m}^{2} /$ day for the mod-still, which is $2.42\left(\mathrm{~L} / \mathrm{m}^{2} /\right.$ day) for the con-still. This indicates a $16.92 \%$ higher mean productivity for the mod-still. The median productivity for the mod-still is $21.95 \%$ higher than the con-still. This higher value in productivity for the mod-still can be attributed to the lower volume of water being kept warm by the heat stored in the concrete pavers and the enabled rising through the pores of the pavers by capillary action. There is then assisted vaporisation in the mod-still, with condensation assisted by the nocturnal cooling of the glass at the night. However, it was observed that these values would have been higher if more room had been made for condensation in both the stills.

Table 9. Important statistics for the con-still and mod-still.

\begin{tabular}{ccc}
\hline Statistical Measures & Con-Still_Obs_Prod (L/m $\mathbf{2} /$ Day) & Mod-Still_Obs_Prod (L/m ${ }^{2} /$ Day) \\
\hline Mean & 2.4243 & 2.8345 \\
Median & 2.4404 & 2.9762 \\
Standard Deviation & 0.9898 & 1.1388 \\
\hline
\end{tabular}

Figure 10 presents a boxplot comparing the productivity of the con-still and mod-still. It is evident that the modified version of the still with incorporated pavers in the basin had higher productivity values. The $25 \%$ quartile of the mod-still is almost equal to the median value of the con-still. Both have equal minimum and maximum values, with the mod-still being a bit higher for each. This can be attributed to the amount of extra heating made available during diurnal hours by the pavers due to their characteristic thermal conductivity.

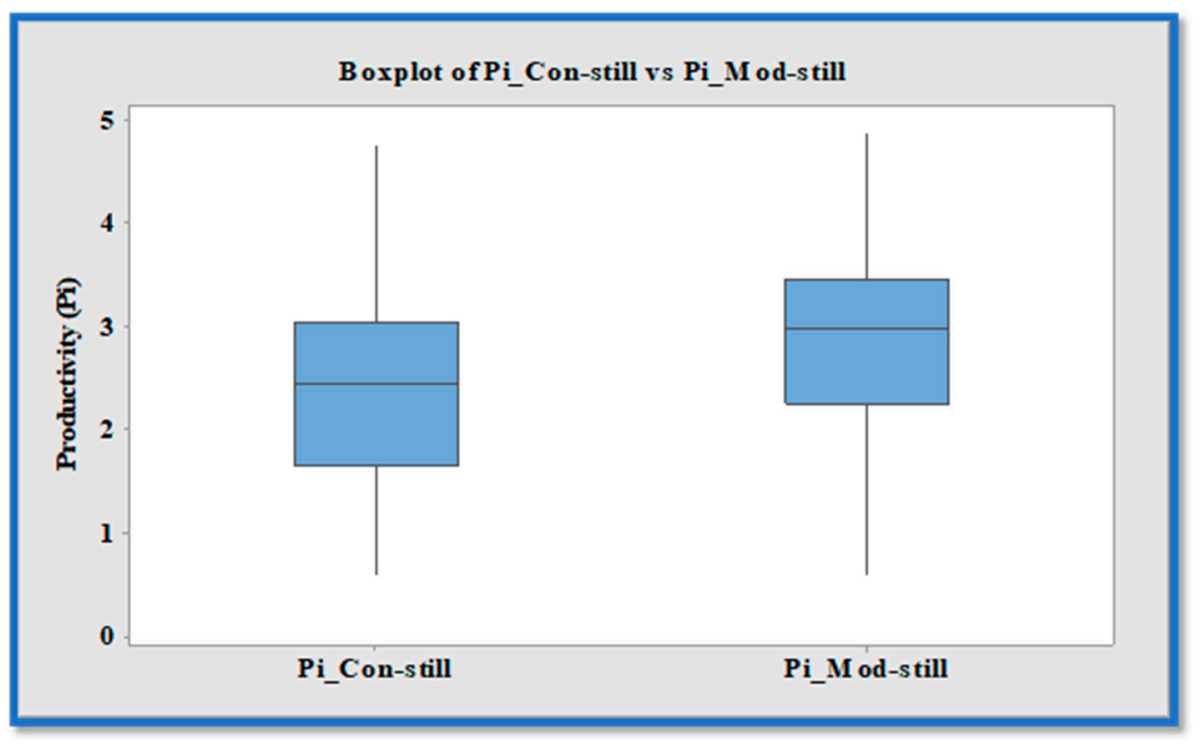

Figure 10. Boxplot of observed productivity values for the con-still and mod-still.

\section{Discussion}

The study was conducted only for about two months at a single location. Ideally, data from about five years at multiple locations should be adopted to develop predictive models, which can be used in practice. Also, a greater number of predictor variables should be considered to enhance the model accuracy. It is also obvious that the higher value of VIF for few variables indicates high correlation between the wind, ambient temperature, and the product of these two. In this study, this is ignored for the time being as it is assumed all these external parameters are independent of the still's internal construction and operation.

The comparison between findings of the current study and the existing literature is crucial to understand the accuracy of the obtained results. Figure 11 illustrates a comparison between the outcomes of our study with the existing literature. 


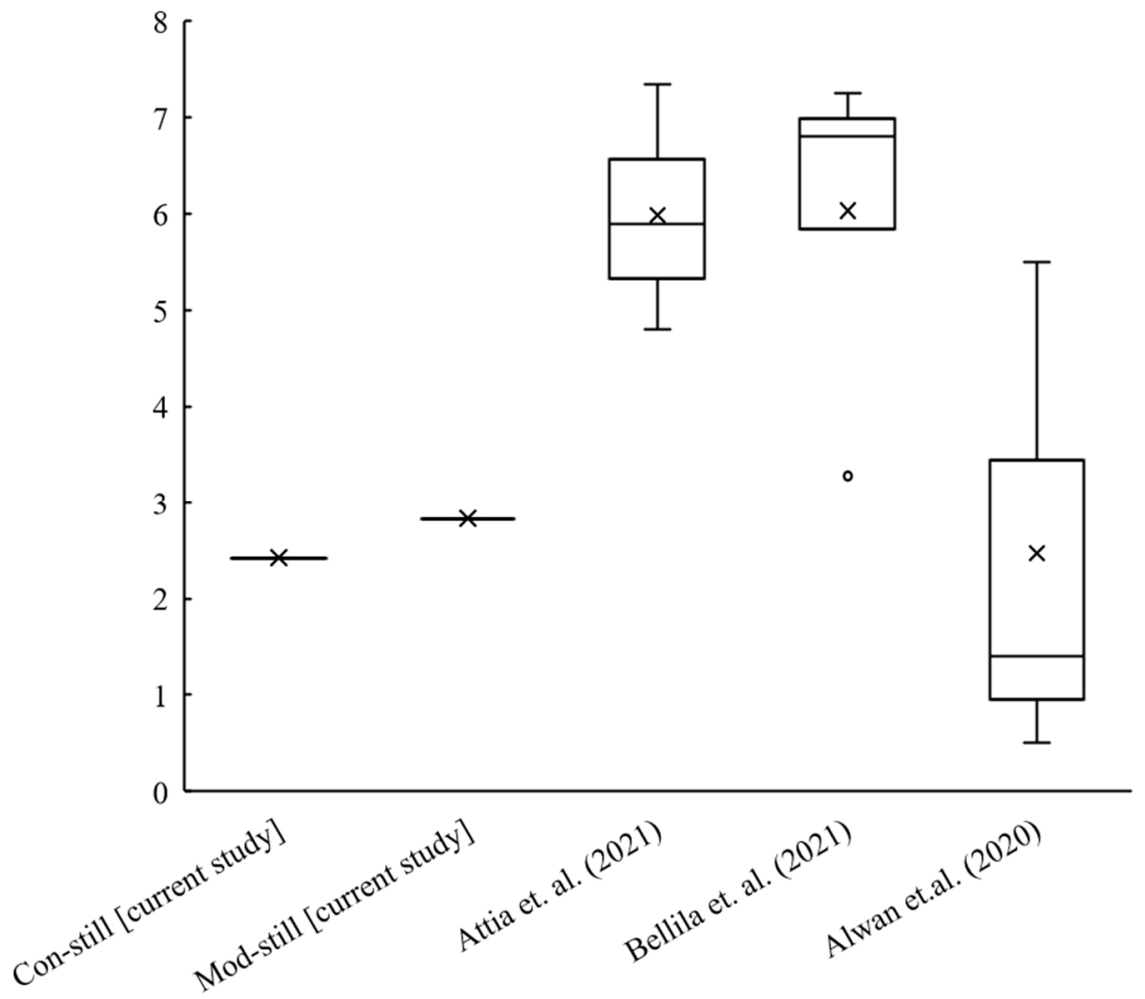

Figure 11. Comparison between results from this study and existing literature. ( $\mathrm{X}$ indicates average value and 0 indicates outlier.

As can be seen from Figure 11, the productivity of the solar still varies between 0.5 to $7.35 \mathrm{~L} / \mathrm{m}^{2} /$ day in the literature depending on the adopted design method and material used for construction. Attia et. al. [18] configured conventional as well as modified hemispherical solar stills using three different types of metals (copper, zinc, and iron). The productivity of the still with copper had the highest efficiency of $57.2 \%$ with a productivity as high as $7.35 \mathrm{~L} / \mathrm{m}^{2} /$ day. This productivity was higher than the mod-still in our study since copper had better heat retention/dispersion capacity and capability. However, copper would be an expensive option for the target communities with respect to this study.

Similarly, Bellila et.al. [19] had $3.28 \mathrm{~L} / \mathrm{m}^{2} /$ day for the conventional still but obtained productivities as high as 6.7 to $7.25 \mathrm{~L} / \mathrm{m}^{2} /$ day using $\mathrm{Al}_{2} \mathrm{O}_{3}$-water-based nanofluid and glass cover cooling as modification. Nonetheless, the method was expensive and required substantial labour. Alwan et. al. [20] had two comparative studies with 0.5 and $3.28 \mathrm{~L} / \mathrm{m}^{2} /$ day as productive for the conventional solar stills. These were compared with other stills having outstanding performances ranging from 1.4 to $7.3 \mathrm{~L} / \mathrm{m}^{2} /$ day. The enhancement in productivity, when compared to that of this study, were due to the incorporation of an outer solar collector. Hence, the productivities of our solar stills are comparable to other studies.

\section{Conclusions}

The purpose of this study was to develop empirical models based on experimental observations to predict the performance of a solar still under a given climate condition. The predictor variables for this study were local climate and operational and feed water conditions. Based on the outcomes of this study, it can be argued that empirical models developed by using independent external variables such as the average global radiation, wind velocity and sky temperature can be successfully used to predict productivity of a solar still.

The daily values of all the independent external variables were logged for the empirical analysis. Data were collected for 55 days in the summer season in Werrington, New 
South Wales, Australia. The use of Minitab $18^{\circledR}$ software was employed to undertake the regression analysis. The mod-still performance surpassed that of the con-still with $17 \%$ mean and $22 \%$ median higher productivity, respectively. The models for the con-still have shown $R^{2}$ values of $37.40 \%, 37.45 \%$, and $43.14 \%$, while those for the mod-still have been $66.43 \%, 68.48 \%$, and $69.11 \%$. These show that the models of mod-still have higher goodness-of-fit than those for the con-still.

It is recommended that the models developed in this study should be enhanced in future studies by the inclusion of other predictor variables, such as "degree-hour" in reference to a new average standard condensation temperature for day and night to identify warming and cooling impacts throughout the $24 \mathrm{~h}$ daily cycle. If the same still is desired to be used in a different location and climate with different feed water concentration and water depth then the models can include respective variables such as water concentration and mass.

Standardising performance models for global comparison of solar stills will require further validation of these models on varieties of design. Further studies are also recommended, such as use of different brine depths, testing at more than one sites for further validation, and experimenting with a longer duration covering varying seasons, preferably for few years.

Supplementary Materials: The following are available online at https:/ /www.mdpi.com/article/10 $.3390 / w 13233373 / \mathrm{s} 1$, Table S1: Analysis of variance for Con-Still (Model 1), Figure S1: Plots of model diagnostics for Model 1 for Con-Still, Figure S2: Plots of model diagnostics for Con-Still (Model 2), Figure S3: Plots of model diagnostics of Con-Still (Model 3).

Author Contributions: E.N. carried out literature review, conducted the experiments, collated data and carried out statistical analysis and drafted the manuscript. R.I. proposed the model forms, analysed data, checked the analyses and revised the manuscript. M.A.A. revised the draft manuscript and ad-dressed comments by the reviewers. A.R. contributed to the statistical analyses and revised the draft manuscript and addressed comments by the reviewers. All authors have read and agreed to the published version of the manuscript.

Funding: There was no funding and ethics approval for this study.

Institutional Review Board Statement: Not applicable.

Informed Consent Statement: Not applicable.

Data Availability Statement: There is no available data.

Acknowledgments: Authors acknowledge Australian Bureau of Meteorology for providing climate data.

Conflicts of Interest: The authors declare no conflict of interest.

\section{References}

1. WHO. Drinking Water. Fact Sheet. 2019. Available online: https://www.who.int/news-room/fact-sheets/detail/drinking-water (accessed on 14 June 2019).

2. Ahsan, A.; Imteaz, M.; Thomas, U.; Azmi, M.; Rahman, A.; Daud, N.N. Parameters affecting the performance of a low cost solar still. Appl. Energy 2014, 114, 924-930. [CrossRef]

3. Balan, R.; Chandrasekaran, J.; Shanmugan, S.; Janarthanan, B.; Kumar, S. Review on passive solar distillation. Desalin. Water Treat. 2011, 28, 217-238. [CrossRef]

4. Nascimento, F.T.D.; Nascimento, C.A.D.; Spilki, F.R.; Staggemeier, R.; Júnior, C.M.L. Efficacy of a solar still in destroying virus and indicator bacteria in water for human consumption. Ambient. Agua-Interdiscip. J. Appl. Sci. 2018, 13, 1-12. [CrossRef]

5. Ahsan, A.; Imteaz, M.; Rahman, A.; Yusuf, B.; Fukuhara, T. Design, fabrication and performance analysis of an improved solar still. Desalination 2012, 292, 105-112. [CrossRef]

6. Ibrahim, A.G.; Allam, E.E.; Elshamarka, S.E. A modified basin type solar still: Experimental performance and economic study. Energy 2015, 93, 335-342. [CrossRef]

7. Madhlopa, A. Theoretical and empirical study of heat and mass transfer inside a basin type solar still. Energy 2017, 136, 45-51. [CrossRef]

8. Malaiyappan, P.; Elumalai, N. Asymmetrical Solar Still with Various Basin Materials. Appl. Mech. Mater. 2015, 812, 14-18.

9. Al-Soud, M.; Akayleh, A. Development of a solar water distillation system with a mechanical sun tracker. Int. J. Ambient. Energy 2017, 40, 212-217. [CrossRef] 
10. Al-Hassan, G.A.; Algarni, S.A. Exploring of Water Distillation by Single Solar Still Basins. Am. J. Clim. Chang. 2013, 2, 57-61. [CrossRef]

11. Badran, O. Theoretical Analysis of Solar Distillation Using Active Solar Still. Int. J. Therm. Environ. Eng. 2010, 3, 113-120. [CrossRef]

12. Xiong, J.; Xie, G.; Zheng, H. Experimental and numerical study on a new multi-effect solar still with enhanced condensation surface. Energy Convers. Manag. 2013, 73, 176-185. [CrossRef]

13. Muftah, A.; Sopian, K.; Alghoul, M. Performance of basin type stepped solar still enhanced with superior design concepts. Desalination 2018, 435, 198-209. [CrossRef]

14. Sarada, S.N.; Bindu, B.H.; Devi, S.R.R.; Gugulothu, R. Solar Water Distillation Using Two Different Phase Change Materials. Appl. Mech. Mater. 2014, 592-594, 2409-2415. [CrossRef]

15. El Jirie, N.B.; Capareda, S.C.; Liu, S.; Akbulut, M. Advanced Solar Still Development: Improving Distilled Water Recovery and Purity via Graphene-Enhanced Surface Modifiers. Front. Environ. Sci. 2020. [CrossRef]

16. Gupta, B.; Kumar, A.; Baredar, P.V. Experimental investigation on modified solar still using nanoparticles and water sprinkler attachment. Front. Mater. 2017, 4, 23. [CrossRef]

17. Karn, A.; Chintala, V.; Kumar, S. An investigation into sky temperature estimation, its variation, and significance in heat transfer calculations of solar cookers. Heat Transf.-Asian Res. 2019, 48, 1830-1856. [CrossRef]

18. Attia, M.E.H.; Kabeel, A.; Abdelgaied, M.; Essa, F.; Omara, Z. Enhancement of hemispherical solar still productivity using iron, zinc and copper trays. Sol. Energy 2021, 216, 295-302. [CrossRef]

19. Bellila, A.; Attia, M.E.H.; Kabeel, A.E.; Abdelgaied, M.; Harby, K.; Soli, J. Productivity enhancement of hemispherical solar still using $\mathrm{Al}_{2} \mathrm{O}_{3}$-water-based nanofluid and cooling the glass cover. Appl. Nanosci. 2021, 11, 1127-1139. [CrossRef]

20. Alwan, N.T.; Shcheklein, S.; Ali, O.M. Experimental investigation of modified solar still integrated with solar collector. Case Stud. Therm. Eng. 2020, 19, 100614. [CrossRef] 